\title{
Effects of thermal boundary conditions, surface radiation and aspect ratio on thermal performance in " $\mathrm{T}$ " shallow cavity
}

\author{
Adel Sahi $^{1}$, Djamel Sadaoui ${ }^{1}$, Bachir Meziani $^{2, a}$ And Kacem Mansouri ${ }^{3}$ \\ 1 Laboratoire de Mécanique, Matériaux et Energétique (L2ME), Faculté de Technologie, Université A. Mira de Bejaia, \\ 06000 Bejaia, Algérie \\ ${ }^{2}$ Laboratoire de Physique Théorique (LPT), Faculté des sciences, Université A. Mira de Bejaia, 06000 Bejaia, Algérie \\ 3 Laboratoire Energétique, Mécanique et Ingénieurie (LEMI), Université B. Bouguerra de Boumerdes, 35000 Boumerdes, Algérie
}

Received 11 March 2014, Accepted 20 May 2014

\begin{abstract}
The main objective of this article is to study the effect of $2 \mathrm{D}$ coupled mode free convection with surface radiation on the fluid flow behavior in an air filled partitioned and shallow cavity subjected to isothermal or insulated boundary conditions. The dimensionless governing equations under Boussinesq approximation are coupled with a radiative model through the boundaries conditions and solved by the finite volume method. The numerical results are discussed in terms of streamlines, isotherms, convective and radiative Nusselt numbers along the cover plate for various aspect ratios $(a, b$ and $c)$, emissivities and Rayleigh number. These results highlighted the condition of the enclosure performance and revealed among other that isothermal boundaries induce better convective heat exchange compared to adiabatic cases. Also, it is noticed that varying aspect ratio $(a)$ causes strong influence on both Nusselt numbers compared to the aspect ratios $(b)$ and $(c)$. The increase of $\left(\epsilon_{o}\right)$ raises $N u_{c o n v}$ and decreases $N u_{\text {rad }}$ slightly. Whereas, an increase of $\left(\epsilon_{C}\right)$ leads to minor changes in $N u_{\text {rad }}$ when $(b)$ or $(c)$ vary, this effect becomes appreciable with increasing $(a)$.
\end{abstract}

Key words: Free convection / surface radiation / isothermal boundary / insulated boundary / Nusselt number

\section{Introduction}

Natural convection heat transfer in enclosures has received considerable attention owing to its importance in many practical applications. Some examples may be found in solar collectors, heat exchangers and electronic cooling devices. A literature survey related to this topic revealed that previous studies are substantially orientated toward the study of concave or triangular enclosures with flat walled geometries; references [1-8] give some ideas about fluid flow and thermal characteristics inside cavities with different boundary conditions. All the aforementioned works showed that the heat transfer is limited by the enclosure area and the inclination has an importance on its performance. The wavy surfaces are suitable techniques to improve the thermal performance of heat transfer devices. Mahmud et al. [9, 10] made a numerical study to examine the free convection inside a vertical or inclined enclosure bounded by two isothermal wavy walls and two adiabatic straight walls. Das et al. [11] analyzed natural convection inside the isothermal enclosure

\footnotetext{
a Corresponding author:

bachir.meziani@univ-bejaia.dz
}

having a wavy bottom and ceiling. Soon thereafter, Dalal et al. [12] analyzed the natural convection problem in two-dimensional square enclosure having three flat walls and the wavy vertical wall consisting of one, two and three undulations. They observed that the cavity inclination angle and the aspect ratio are the most important parameters affecting the heat and fluid flow. Ridouane and coworkers [13] investigated flow and thermal characteristics in square, rectangular, arc-shape and circular cavities. The results indicate that there is no appreciable distinction between the square and the circular cavities. In addition, Adjlout [14] and Aounallah [15] reported natural convection in an inclined cavity with right hot wavy wall and left cold flat wall. One of their interesting findings was that the average heat transfer decreases with the surface waviness compared with the flat wall cavity. Saha et al. [16] solved a natural convection problem for sinusoidal and inclined corrugation geometry and concluded that for different heat source sizes, the average Nusselt number increases with increasing inclination angle. Later, Hussain et al. [17] investigated the effect of inclination angles of the thin adiabatic baffle located inside a sinusoidal corrugated enclosure with different corrugation frequencies. The results illustrate that 


\section{Nomenclature}

\begin{tabular}{|c|c|}
\hline$a, b, c$ & Enclosure aspect ratio $\left(a=H_{1} / L_{1} ; b=H_{2} / L_{1} ; c=L_{2} / L_{1}\right)$ \\
\hline$C_{p}$ & Specific heat at constant pressure $\left(\mathrm{J} \cdot \mathrm{kg}^{-1} \cdot \mathrm{K}^{-1}\right)$ \\
\hline$F$ & Shape factor \\
\hline$g$ & Gravitational acceleration $\left(\mathrm{m} \cdot \mathrm{s}^{-2}\right)$ \\
\hline$G r$ & Grashof number $G r=R a / P r$ \\
\hline$H, L$ & Height, length (m) \\
\hline$j(J)$ & Dimensional (Dimensionless $J=j / \sigma T_{H}^{4}$ ) radiosity $\left(\mathrm{W} . \mathrm{m}^{-2}\right.$ ) \\
\hline$k$ & Thermal conductivity $\left(\mathrm{W} \cdot \mathrm{m}^{-1} \cdot \mathrm{K}^{-1}\right)$ \\
\hline$N u_{x}$ & Local Nusselt number \\
\hline$N u$ & Average Nusselt number \\
\hline$N_{r}$ & Dimensionless net radiation number $N_{r}=\sigma T_{H}^{4} /(k \Delta T / L)$ \\
\hline$p(P)$ & Dimensional (Dimensionless $P=p L^{2} / \rho \nu^{2}$ ) pressure $(\mathrm{Pa})$ \\
\hline $\operatorname{Pr}$ & Prandtl number \\
\hline$q_{r}\left(Q_{r}\right)$ & Dimensional (Dimensionless $Q_{r}=q_{r} /\left(\sigma T_{H}^{4}\right)$ ) net radiative flux density (W.m ${ }^{-2}$ ) \\
\hline$R a$ & Rayleigh number \\
\hline$T$ & Temperature $\left(\mathrm{K}^{-1}\right)$ \\
\hline$v_{i}\left(V_{i}\right)$ & Dimensional (Dimensionless $\left.V_{i}=v_{i} L / \nu\right)$ velocity components $\left(\mathrm{m} \cdot \mathrm{s}^{-1}\right)$ \\
\hline$x_{i}\left(X_{i}\right)$ & Dimensional (Dimensionless $\left.X_{i}=x_{i} / L\right)$ Cartesian coordinates $(\mathrm{m})$ \\
\hline \multicolumn{2}{|r|}{ Greek symbol } \\
\hline$\rho$ & Density $\left(\mathrm{kg} / \mathrm{m}^{-3}\right)$ \\
\hline$\alpha$ & Thermal diffusivity $\left(\mathrm{m}^{2} . \mathrm{s}^{-1}\right)$ \\
\hline$\beta$ & Thermal expansion coefficient $\left(\mathrm{K}^{-1}\right)$ \\
\hline$\mu$ & Dynamic viscosity $\left(\mathrm{kg} \cdot \mathrm{s}^{-1} \cdot \mathrm{m}^{-1}\right)$ \\
\hline$\nu$ & Kinematic viscosity $\left(\mathrm{m}^{2} \cdot \mathrm{s}^{-1}\right)$ \\
\hline$\sigma$ & Stefan - Boltzmann constant $\sigma=5.67 \times 10^{-8}\left(\mathrm{~W} \cdot \mathrm{m}^{-2} \cdot \mathrm{K}^{-4}\right)$ \\
\hline$\epsilon$ & Emissivity \\
\hline$\theta, \Theta$ & Dimensionless temperature $\theta=\left(T-T_{C}\right) /\left(T_{H}-T_{C}\right), \Theta=T / T_{H}$ \\
\hline$\Psi$ & Dimensionless stream function $\Psi=\psi / \nu$ \\
\hline \multicolumn{2}{|r|}{ Subscripts } \\
\hline$H, c$ & Hot and cold \\
\hline 1,2 & Enclosure and microcavity \\
\hline $\operatorname{conv}, \mathrm{rad}$ & Convection and radiation \\
\hline
\end{tabular}

for different baffle inclination, the average Nusselt number increases with increasing in both the Grashof number and corrugation frequency. Mahmoud et al. [18] focused in their paper on the feasibility of using neural networks to predict the thermal and flow parameters throughout a partitioned cavity under steady state, laminar, twodimensional and natural convective flow. The results show excellent prediction when the neural networks are properly designed. Recently, Bakkas et al. [19] reported in their paper a series of numerical simulations of laminar steady state and natural convection flow inside a two dimensional horizontal channel containing heating rectangular blocks, periodically mounted on its lower wall. The results obtained show that the fluid flow and temperature fields are strongly influenced by the blocks height and the distance between two contiguous blocks. In thermal solar applications, the collectors are designed usually as shallow enclosures but their absorbers can take different geometries such as flat, wavy or corrugated. Gao et al. [20] made analytical and experimental studies to investigate the thermal performance of cross-corrugated solar air-heaters in which the wave like shapes of the absorbing plate and the bottom plate are perpendicular to each other. It is also found that the use of selected coatings on the absorbing plates can substantially enhance the thermal performances of the heaters. In a similar problem, a numerical simulation of natural convection heat transfer and fluid flow are performed respectively for horizontal and inclined solar collectors $[21,22]$. The results presented show that flow and thermal fields are strongly affected by the shape of enclosure and the heat transfer rate increases in wavy enclosure case comparatively with the flat enclosure. A thorough analysis conducted recently by Chen et al. [23] on convection heat transfer in three types of concave enclosure shows that the effects of various shapes, the strength of the vortex are relatively bigger in the rectangular-rectangular concave enclosure than in the rectangular-circular concave enclosure at the same Grashof number. More recently, an experimental analysis conducted by Greig [24] on the air flow behavior in a vertical channel bounded by a transpired air collector corrugated surface and a plane construction wall showed that the corrugation waveform substantially modified both mean and turbulent flow structure inside 
the channel. In another approach, Nasrin [25] investigated numerically the laminar free convection in a solar collector with a flat cover and wavelike absorber filled with a water-alumina nanofluid. It's observed that the heat transfer improvement is more effective for the nanofluid than the base fluid. It is worthy to note that, some other important investigations concerning the heat transfer in cavities bounded with rigid and no thickness walls subjected to various boundary conditions were conducted by Ferahta [26], Greig [27] and Huang [28]. The preceding literature review shows that available studies are generally limited to free convection without surface radiation. However, the conjugate thermal radiation with convection in cavities filled with transparent or semi transparent fluid has received considerable attention over the past few decades in view of the numerous potential applications such as thermal insulations, combustion, electronic cooling systems, industrial furnaces, nuclear reactor safety and solar collectors. Reviews on this subject can be found in the publications of Balaji [29,30], Kuyper [31], Akiyama [32], Ramesh [33], Desrayaud [34], Sing [35], Wang [36], Mezrhab [37], Alvarado [38], Rabhi [39], Kuznetsov [40], Nouanegue [41], Mondal [42], Vivek [43] and $\mathrm{Li}[44]$. It is namely revealed that the surface radiation alters markedly the basic flow pattern in enclosures and thermal performances are affected by the partition configuration. It's also found that free convection heat transfer when coupled with radiation had a greater contribution compared to systems governed by forced convection. As it can be seen, the literature related to thermal radiation coupled with convection is not as rich as without surface radiation. Therefore, the fluid flow and heat transfer phenomena in the corrugated enclosure need a more comprehension. The present paper investigates numerically the steady state laminar conjugate free convection and surface radiation in a partitioned shallow cavity. However, to the best of the authors' knowledge, there is rather little work with enclosures of this type and even less with these boundary conditions usually encountered in solar collectors. In this regard, when thermal radiation is not considered, reference [23] is alone to work on this kind of geometry with isothermal boundary conditions. Special attention will be paid to the effects of pertinent parameters such as boundary conditions, Rayleigh number, geometric ratios and surface emissivities on flow patterns and heat transfer. The results obtained are compared with the available references and presented in term of streamlines, isotherms and Nusselt numbers.

\section{Problem description and mathematical formulation}

\subsection{Description of the physical model}

Computational domain and boundary conditions are shown schematically in Figure 1. The physical model of $2 \mathrm{D}$ shallow cavity filled with a transparent fluid under consideration consists of two vertical sides and two horizontal surfaces with shaped part on the bottom. Two different cases of boundary conditions were considered, in the first case I: the upper wall is maintained at a cold temperature $\left(T_{C}=308 \mathrm{~K}\right)$ and the other remaining surfaces are at a fixed warm temperature $\left(T_{H}=318 \mathrm{~K}\right)$ (i.e. the configuration investigated in reference [23] without surface radiation). In the case II: the temperature of the bottom and upper walls are respectively $T_{H}=318 \mathrm{~K}$ and $T_{C}=308 \mathrm{~K}$ with thermally insulated sides at the upper concave cavity. All surfaces are assumed gray, diffuse and opaque with the emissivities $\left(\epsilon_{C}\right),\left(\epsilon_{H}\right)$ and $\left(\epsilon_{L}=\epsilon_{R}=\epsilon_{o}\right)$ for the top, bottom and vertical sides, respectively. In these figures, $H_{1}, L_{1}$ and $H_{2}, L_{2}$ shows the height and the length of the enclosure and the microcavity, respectively. For commodity, these parameters are defined in terms of geometric ratios such as: $a=H_{1} / L_{1}$, $b=H_{2} / L_{1}$ and $c=L_{2} / L_{1}$.

\subsection{Mathematical formulation}

The numerical model for heat transfer and fluid flow in the partitioned enclosure was developed under some assumptions as steady state, laminar and incompressible Newtonian fluid. Viscous dissipation and compressibility effects are neglected. Also, the fluid properties are assumed constant except the density in the buoyancy term of the momentum equations, which can be approximated by the Boussinesq approach. The mathematical formulation governing the two dimensional fluid flow and heat transfer can be written on dimensionless form as:

$$
\begin{aligned}
\frac{\partial V_{i}}{\partial X_{i}} & =0 \\
V_{j} \frac{\partial V_{i}}{\partial X_{j}} & =-\frac{\partial P_{i}}{\partial X_{i}}+\frac{\partial^{2} V_{i}}{\partial X_{j} \partial X_{j}}+\frac{R a}{P r} \theta \delta_{i 2} \\
V_{j} \frac{\partial \theta}{\partial X_{j}} & =\frac{1}{\operatorname{Pr}} \frac{\partial^{2} \theta}{\partial X_{j} \partial X_{j}}
\end{aligned}
$$

where $R a$, and $\operatorname{Pr}$ are respectively the Rayleigh and Prandtl number defined respectively by: $R a=g \beta\left(T_{H}-\right.$ $\left.T_{C}\right) L^{3} / \nu \alpha$ and $\operatorname{Pr}=\nu / \alpha$. In the above equations, $P, \theta$ are the dimensionless pressure and temperature while $X_{i}$ and and $V_{i}$ are the dimensionless Cartesian coordinates and corresponding velocity components respectively. Assuming the non slip flow, the relevant dimensionless boundary conditions can be written as follows:

$$
\begin{gathered}
- \text { Case I } \\
V_{i}=0 \text { and } \theta=0 \text { and } \epsilon_{C} \text { (upper wall) } \\
V_{i}=0 \text { and } \theta=1 \text { and } \epsilon_{H} \text { (remaining surfaces) }
\end{gathered}
$$

- Case II

$$
\begin{gathered}
V_{i}=0 \text { and } \theta=0 \text { and } \epsilon_{C} \text { (upper wall) } \\
V_{i}=0 \text { and } \theta=1 \text { and } \epsilon_{H} \\
\text { (bottom and microravity sides) }
\end{gathered}
$$



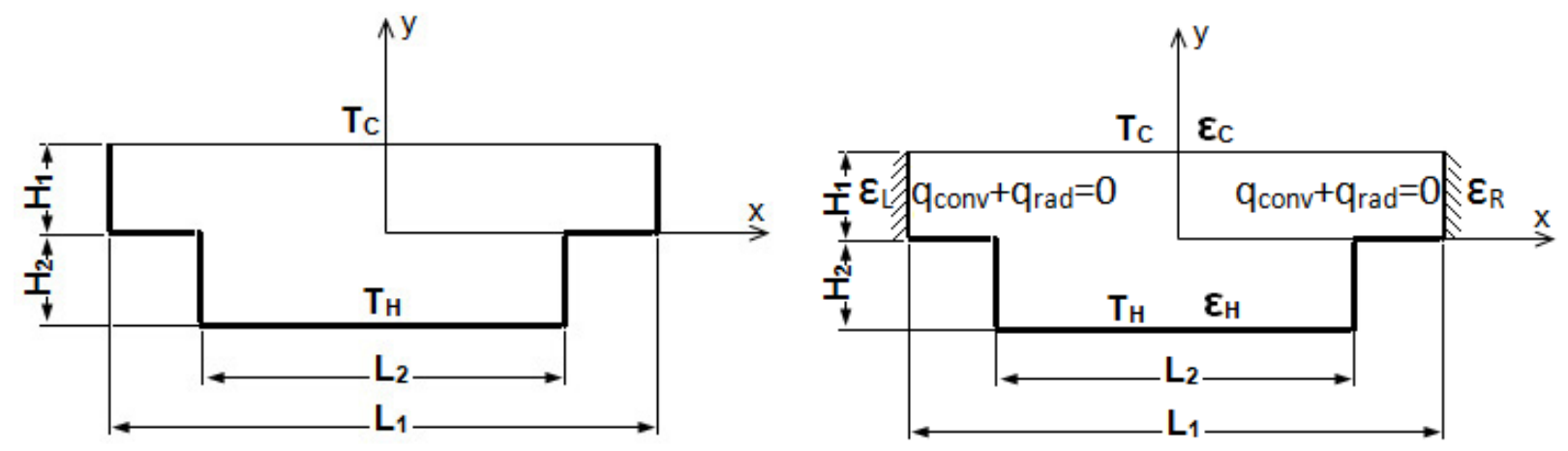

Fig. 1. Physical domain.

$$
\begin{aligned}
V_{i}=0 \quad \text { and } \quad & \pm \frac{\partial \theta}{\partial X_{1}}+N_{r} Q_{r}=0 \\
\text { and } \epsilon_{L} & =\epsilon_{R}=\epsilon_{o} \quad \text { (upper vertical sides) }
\end{aligned}
$$

\subsection{Radiation description}

The radiation heat transfer is computed using the radiosity formulation. All the enclosure walls are assumed to be gray, diffuse and opaque with different emissivities. The cavity is filled with a radiatively non-participating fluid (air, $\operatorname{Pr}=0.71$ ) so only solid surfaces contribute to the radiation exchange. Thus, the radiative heat transfer is made only through the thermal boundary conditions.

The dimensionless radiosity equation for the ith surface of the enclosure $(J)$ is defined as:

$$
J_{i}=\epsilon_{i} \Theta_{i}^{4}+\left(1-\epsilon_{i}\right) \sum_{j=1}^{N}\left(J_{j} F_{i j}\right)
$$

So the dimensionless net radiative heat flux $\left(Q_{r, i}\right)$ along the $i$ th discrete surface is determined by:

$$
Q_{r, i}=J_{j}-\sum_{j=1}^{N}\left(J_{j} \cdot F_{i j}\right) i=1,2, \ldots, N
$$

where $(N)$ is the number of total radiative surfaces along the boundaries of the enclosure, $\epsilon_{i}$ the emissivity of the $i$ th surface while the shape factor $F_{i, j}$ from the $i$ th element to the $j$ th element of the enclosure is determined using HottelŠs crossed string method [45]. To determine heat transfer characteristics at the enclosure walls, contributions of both convection and radiation should be taken into account. The mean Nusselt number, is used to evaluate the rate heat transfer on enclosure surfaces. Thus, the global average Nusselt number along the cold wall is defined as the sum of convective and radiative Nusselt-numbers.

$$
N u=N u_{\text {conv }}+N u_{\text {rad }}=-\int_{-\frac{1}{2}}^{\frac{1}{2}} \frac{\partial \theta}{\partial Y} \mathrm{~d} X+\int_{-\frac{1}{2}}^{\frac{1}{2}} N_{r} Q_{r} \mathrm{~d} X
$$

\section{Numerical approach and validation}

The mass, momentum and energy balance (Eqs. (1)-(3)) with the specified boundary conditions (Eqs. (4)-(5)) are solved numerically by the finite volume method under non-uniform grid system in $x$ and $y$ directions. The solver specified uses a pressure correction based on iterative SIMPLER algorithm. The advective terms are discretized using a QUICK scheme whereas a second-order central difference scheme is applied for the diffusion terms (for more details, see Ref. [46]). To check the convergence of the sequential iterative solution, the normalized residual is calculated for the mass, momentum and energy equations. The convergence is obtained when the residual becomes smaller than $10^{-7}$. To find a proper grid size, a grid testing which consists to check the results obtained for various grid sizes varying from $61 \times 61$ to $181 \times 181$ is performed. The multiple-block grid system employed is shown in Figure 2.

In this section, a grid independence test is carried out using the basic model [23] corresponding to simple natural convection in concave partitioned enclosure $(a=1 / 6$, $b=1 / 6, c=2 / 3$ and $\left.G r=10^{4}-2 \times 10^{5}\right)$. Furthermore, extensive validations of the developed code for coupled radiation and natural convection in square cavity have been also validated against the results reported by Wang [36]. The computations have been performed in term of mean Nusselt for various Rayleigh numbers $\left(10^{4}-10^{6}\right)$.

As listed in Table 1, the average Nusselt number remains almost the same for grids finer than $121 \times 121$ and heavily depends on the grid size for less finer grids for both studies. Nevertheless, similar tests were conducted for other Rayleigh numbers and the grid size was adjusted accordingly. The comparisons are in excellent agreements, providing sufficient confidence in present computations. Hence, considering both the accuracy and the computational costs, most computations reported in this study were performed with a multiple grid system of $151 \times 151$.

\section{Results and discussion}

To understand the heat transfer mechanisms occurring usually in air solar collectors, different scenarios for 

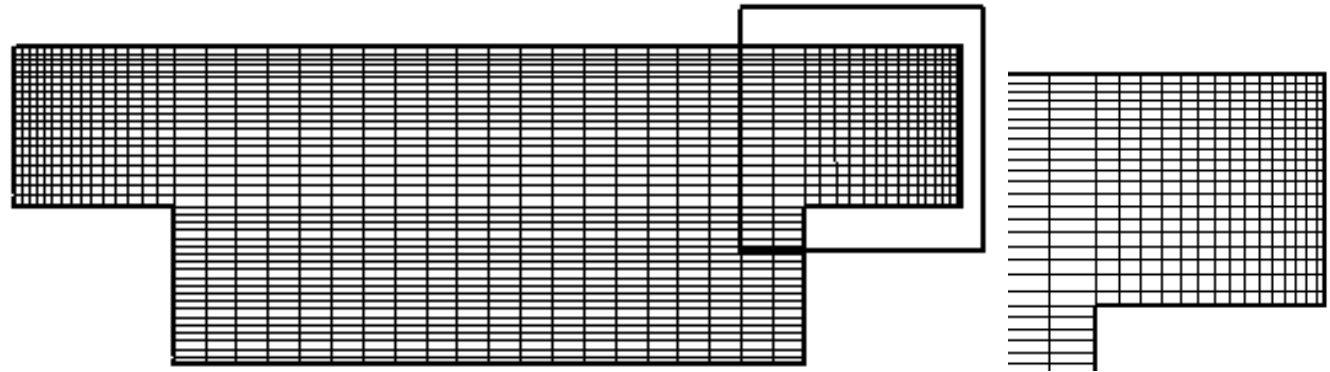

Fig. 2. Detail of the computational grid within the partitioned enclosure.

Table 1. Effect of grid size on the mean Nusselt number, comparison with reference [23] (without surface radiation $\epsilon=0$ ) and reference [36] (coupled mode $\epsilon \neq 0$ ).

\begin{tabular}{cccccccccc}
\hline \multicolumn{3}{c}{ Partitioned cavity $\left(\epsilon_{i}=0\right)[23]$} & \multicolumn{5}{c}{ Squar cavity $\left(\epsilon_{i} \neq 0\right)[36]$} \\
\hline Grid & \multicolumn{3}{c}{ Nu } & \multicolumn{4}{c}{$N u_{\text {rad }}$} & \multicolumn{3}{c}{$N u_{\text {conv }}$} \\
& Gr & Current & {$[23]$} & $R a$ & $\epsilon$ & Current & {$[36]$} & Current & {$[36]$} \\
\hline $61 \times 61$ & & 10.235 & & & & 11.246 & & 8.083 \\
$91 \times 91$ & & 10.829 & & & & 11.243 & & 7.989 & \\
$121 \times 121$ & $10^{4}$ & 11.034 & 11.132 & $10^{6}$ & 0.8 & 11.241 & 11.150 & 7.950 & 7.930 \\
$151 \times 151$ & & 11.051 & & & & 11.240 & & 7.937 & \\
$181 \times 181$ & & 11.059 & & & & 11.240 & & 7.933 & \\
& $5 \times 10^{4}$ & 13.932 & 13.914 & $10^{6}$ & 0.2 & 2.341 & 2.319 & 8.400 & 8.417 \\
& $1 \times 10^{5}$ & 15.471 & 15.582 & $10^{5}$ & 0.2 & 1.088 & 1.073 & 4.415 & 4.411 \\
$151 \times 151$ & $2 \times 10^{5}$ & 17.607 & 17.704 & $10^{5}$ & 0.8 & 5.183 & 5.137 & 4.250 & 4.247 \\
& & & & $10^{4}$ & 0.2 & 0.504 & 0.499 & 2.268 & 2.268 \\
& & & & $10^{4}$ & 0.8 & 2.387 & 2.372 & 2.279 & 2.278 \\
\hline
\end{tabular}

conjugate natural convection and surface radiation in a partitioned enclosure were explored. For a comparison purpose, Rayleigh number, aspect ratio ( $a, b$ and $c$ ), boundary conditions (cases I and II) and surface emissivities $\left(\epsilon_{C}, \epsilon_{H}\right.$ and $\left.\epsilon_{O}\right)$ are considered as the main effective parameters for the combined mode of heat transfer. The Prandtl number is fixed at $\operatorname{Pr}=0.71$.

\subsection{Temperature and fluid pattern in absence of surface radiation}

\section{Pure convection mode $\left(\epsilon_{i}=0\right.$ without surface radiation)}

Buoyancy driven flow and temperature field inside the enclosure are given by means of streamlines and isotherms. The Figures 3-5, illustrate the effect of Rayleigh number and aspect ratios on the flow pattern and temperature contours in the "T" enclosure for both cases. The force circulation of the flow within the cavity takes place by virtue of thermal buoyancy which is represented by the Rayleigh number $R a$. For small values of $R a\left(10^{4}\right)$, the fluid motion involves two primary and symmetric recirculating eddies of relatively weak velocity extending throughout the partitioned cavity with clockwise and anti-clockwise rotations $\left(\Psi_{\max } \leq 0.3\right)$. The isotherms plots are smooth curves which cover the entire enclosure and present a symmetric behavior about the vertical axis indicating that the conduction is the dominant heat transfer mechanism. The isotherms values change smoothly from the hot to the cold wall with decreasing from the bottom to the top along the vertical center line, thermal stratification reigns in the entire domain. With the increase of $R a$, due to the important temperature gradient generates the faster recirculation rolls $\left(5.93 \leq \Psi_{\max } \leq 28.25\right)$. The convection increases significantly and becomes stronger, such that stratification decreases in the center of the cavity and a multi-cell structure prevails in the enclosure. For $R a=10^{6}$, the stronger cells are formed and the flow is characterized by a multicellular structure within the enclosure. By using the same boundary conditions for the left and right walls, the pairs of cells are close to each other and present a similar symmetric shape about the vertical center line. Each pair of cells rotates in the clockwise and in counterclockwise directions, respectively. Thus increasing $R a$ promotes the convection heat transfer mechanism against conduction. It is clearly observed that the buoyancy strength induces the increasing vortices for higher $R a$; this is owing to the dominating influence of the convective current in the cavity. Also, increasing $R a$ number leads to the appearance of thermal boundary near the upper wall and promotes the convection heat transfer mechanism against conduction.

The streamlines and isotherms structures change with the variation of the enclosure dimensions. Indeed the effects of both dimensionless shape parameters $(a)$ and $(b)$ on the flow pattern and temperature distribution are illustrated in Figures 3 and 4. The flow is decelerated and the isotherms are denser near the cold wall when the aspect ratio $(a)$ decreases ( $b$ increases) involving the appearance of cells in the symmetrical corners of the cavity. 


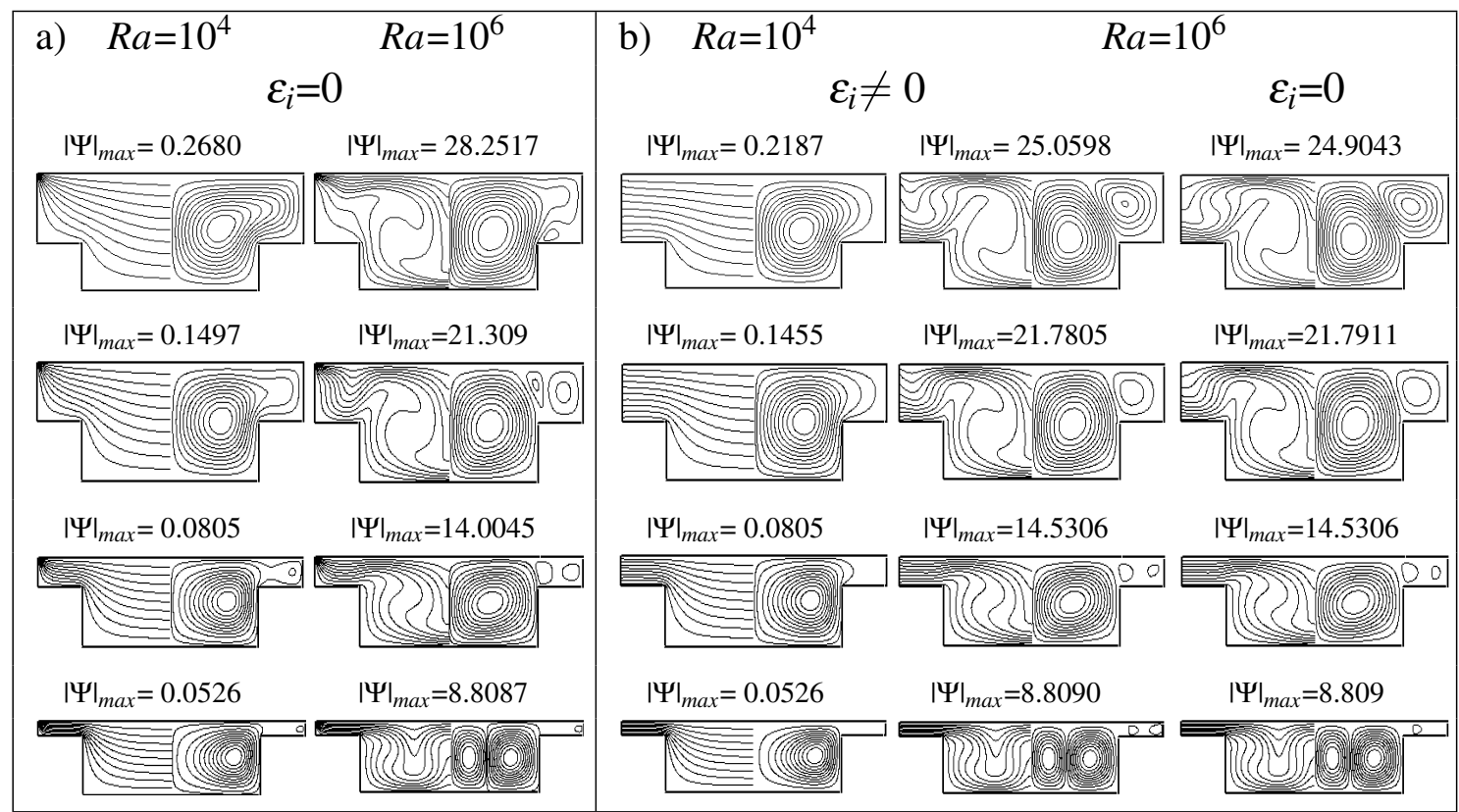

Fig. 3. Streamlines (right) and isotherms (left): $b=1 / 6 ; c=2 / 3$ and $a=1 / 4,1 / 6,1 / 12$ and $1 / 24$. (a) Case I: (pure convection $\left.\epsilon_{i}=0\right)$. (b) Case II: $\left(\epsilon_{C}=0.9 ; \epsilon_{H}=1\right.$ and $\left.\epsilon_{o}=0.5\right)$ or $\left(\epsilon_{i}=0\right)$.

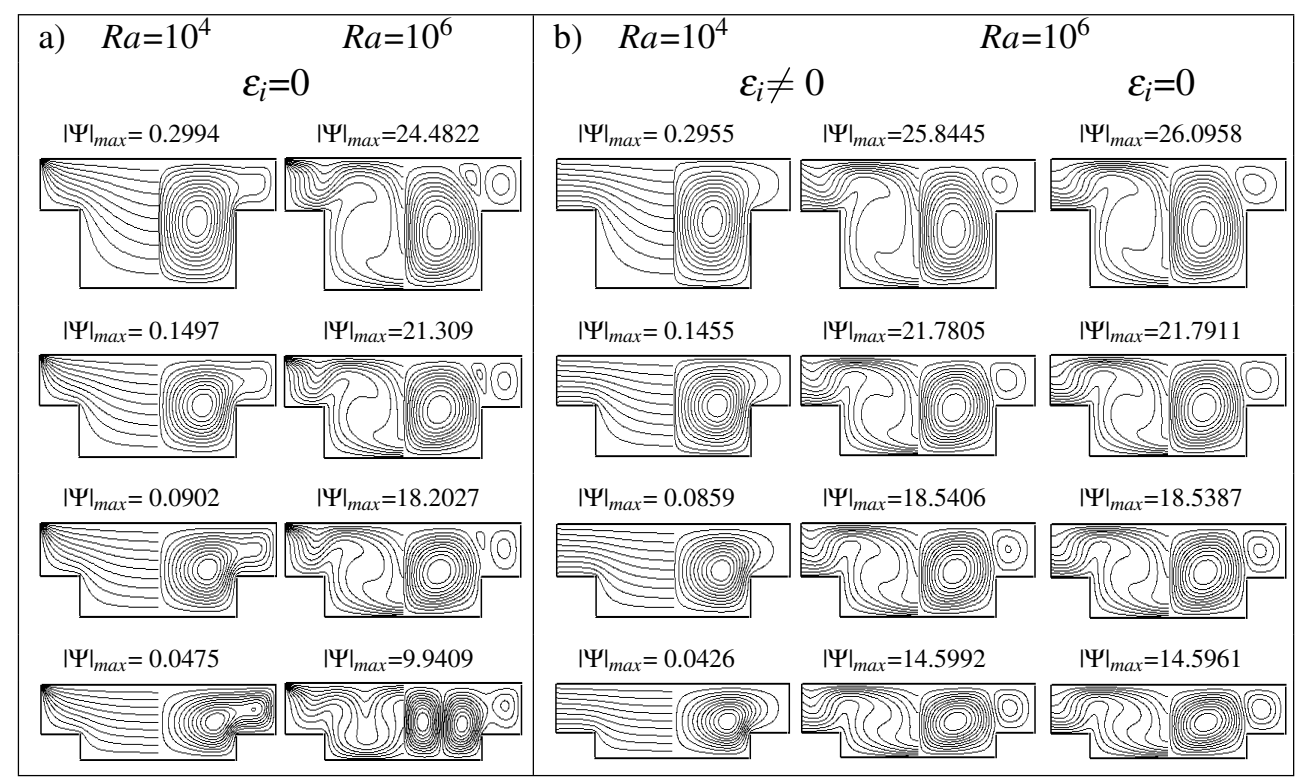

Fig. 4. Streamlines (right) and isotherms (left): $a=1 / 6 ; c=2 / 3$ and $b=1 / 4,1 / 6,1 / 8$ and $1 / 12$. (a) Case I: (pure convection $\left.\epsilon_{i}=0\right)$. (b) Case II: $\left(\epsilon_{C}=0.9 ; \epsilon_{H}=1\right.$ and $\left.\epsilon_{o}=0.5\right)$ or $\left(\epsilon_{i}=0\right)$.

With decreasing the parameter $(a)$ (respectively $(b))$; central cells become squeezed in the core region. It is clearly observed that flow pattern in the core region consists of a symmetric descending bi-cellular flow with the same strength order (for $a \geq 1 / 12$ or $b \geq 1 / 8$ ) which becomes multicellular (for $a=1 / 24$ or $b=1 / 12$ ). This transition of the flow pattern strongly depends on the buoyant flow $R a$ and shape parameters $(a)$ and $(b)$.

The increasing flow within the whole partitioned enclosure is accompanied by the significant distortion in the temperature contours, especially in the central region.
The temperature contours change significantly and are denser near the cold wall. Isothermal plumes appear and turn back towards the hot wall indicating a strong heat transfer in this region. The parameters governing the plume formation are Rayleigh number and the aspect ratio $(a)$ and $(b)$. Moreover, the temperature contours are concentrated and compressed toward isothermal walls.

As illustrated in Figure 5 when reducing the aspect ratio $(c)$ (length $L_{2}$ ) the symmetry of the flow still maintained (cf. Figs. 3 and 4). The fluid flow is decelerated and central cells are squeezed involving the appearance 


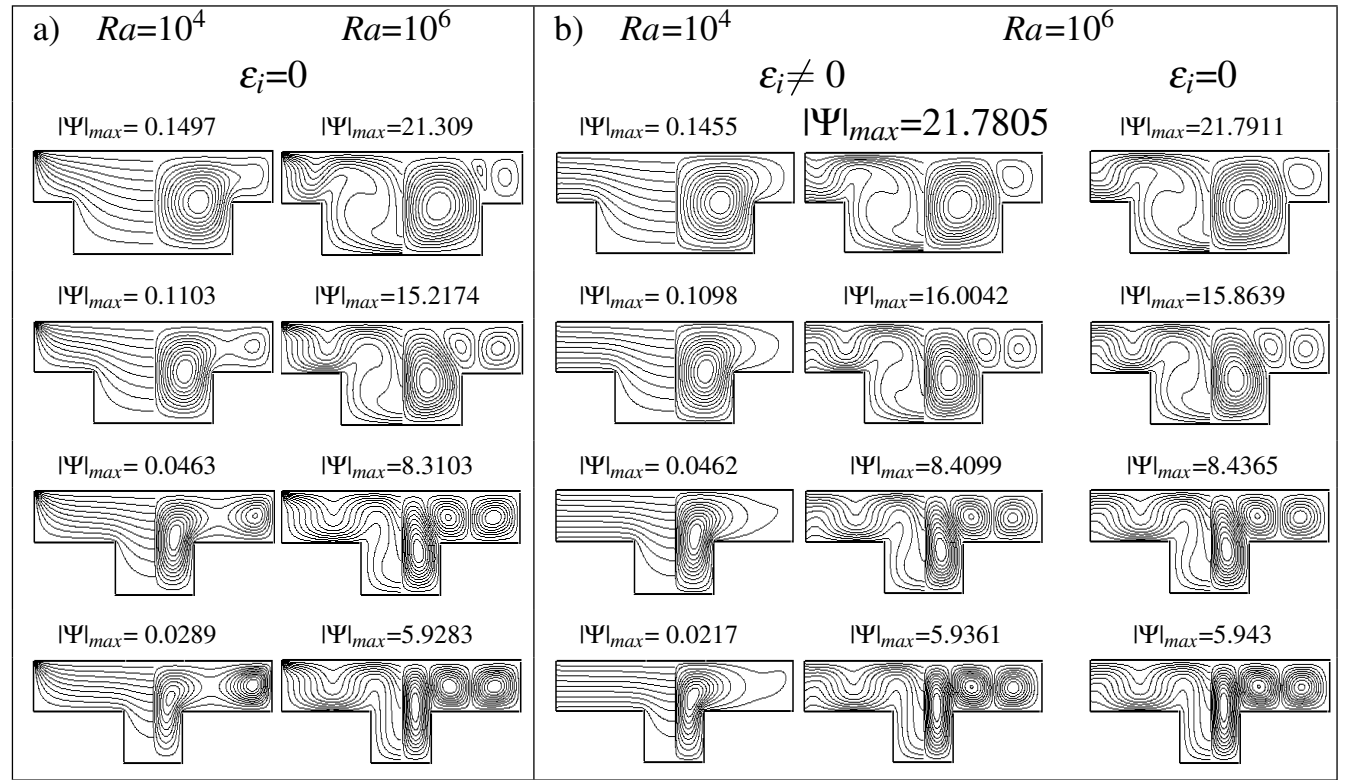

Fig. 5. Streamlines (right) and isotherms (left): $a=1 / 6 ; b=2 / 3$ and $c=2 / 3,1 / 2,1 / 3$ and $1 / 4$. (a) Case I: (pure convection $\left.\epsilon_{i}=0\right)$. (b) Case II: $\left(\epsilon_{C}=0.9 ; \epsilon_{H}=1\right.$ and $\left.\epsilon_{o}=0.5\right)$ or $\left(\epsilon_{i}=0\right)$.

of minor rolls in the corners of the cavity. Thus the bicellular structure observed for $c=2 / 3$ changes into a multi-cells structure at low $(c)$ values $(\leq 1 / 2)$ due to the weaker upslope flows. By increasing $R a$, the isotherms change from stratification to thermal plume behavior into the entire cavity.

\section{Coupled mode $\left(\epsilon_{i} \neq 0\right.$; convection with surface radiation)}

The same Figures 3b, 4b and 5b also allow us to analyse the surface radiation effect on the isotherms and the streamlines shape. According to the mathematical model, especially in view of the boundary conditions it is clear that surface radiation does not alter the flow field in the core region. The changes in thermal boundary conditions may lead to large effects on the flow structure and heat transfer near the insulated walls, consequently modify the overall Nusselt number. Indeed, for the second configuration when $\epsilon_{i}=0$ (pure convection) isotherms are normal to the insulated walls whereas in coupled mode $\left(\epsilon_{i} \neq 0\right)$ isotherms appear inclined due to the radiative heat exchange which in turn alters significantly the gradient temperature near the adiabatic walls. So the temperature distribution at the adiabatic walls depends on the heat exchange by both convection and surface radiation. Surface radiation relatively weakens gradient of the thermal boundary near the isothermal sides and results in a decrease of convection heat transfer.

\subsection{Heat transfer analysis}

\subsubsection{Local Nusselt number}

Heat transfer rate is presented in terms of the local and the average Nusselt number. For the considered cases
(I and II), Figures 6a and 6b depict the variation of local convective and radiative Nusselt numbers, $N u_{x_{\text {conv }}}$ and $N u_{x_{\text {rad }}}$, along the cold wall at various Rayleigh numbers $\left(R a=10^{3}-10^{6}\right)$.

The curves drawn for $N u_{\text {rad }}$ and $N u_{\text {conv }}$ against $X$ show that for all Rayleigh numbers, the local Nusselt values are symmetric with respect $X=0$. The peaks observed in convective Nusselt numbers, correspond to the tightening of the thermal boundary layer along the cold wall. The minimum heat transfer rate, resulting from the relaxation of the thermal boundary layer occurs at the middle wall as seen from streamlines and isotherms contours. As a result of decreasing $R a$ number, the rate of convective heat transfer along this wall decreases so that curves become gradually smooth and tend to those of the conduction regime $\left(R a \leq R a_{c}\right)$. The contribution of radiative walls in case II is also shown in Figure 6b, thus the largest values of $N u_{\text {rad }}$ correspond to the highest values of $R a$. For a fixed $R a$ the local radiative Nusselt number follows a parabolic form with strong gradients near the extremities. Whereas away from these singularities the surface radiation has no significant effect and the $N u_{\text {rad }}$ remains constant. It is noteworthy that in the absence of thermal radiations the total Nusselt number coincides with the convective Nusselt (when $\epsilon_{i}=0$ ).

\subsubsection{Influence of Rayleigh number and aspect ratios on mean Nusselt number}

The variation of the average Nusselt number calculated by integrating the local Nusselt distribution is utilized to evaluate the overall heat transfer rate and is investigated for different values of $R a$ number as illustrated in Figures $7-10$. To highlight the effects of the cavity dimensions $\left(H_{1}, H_{2}\right.$ and $\left.L_{1}\right)$ on the heat transfer 


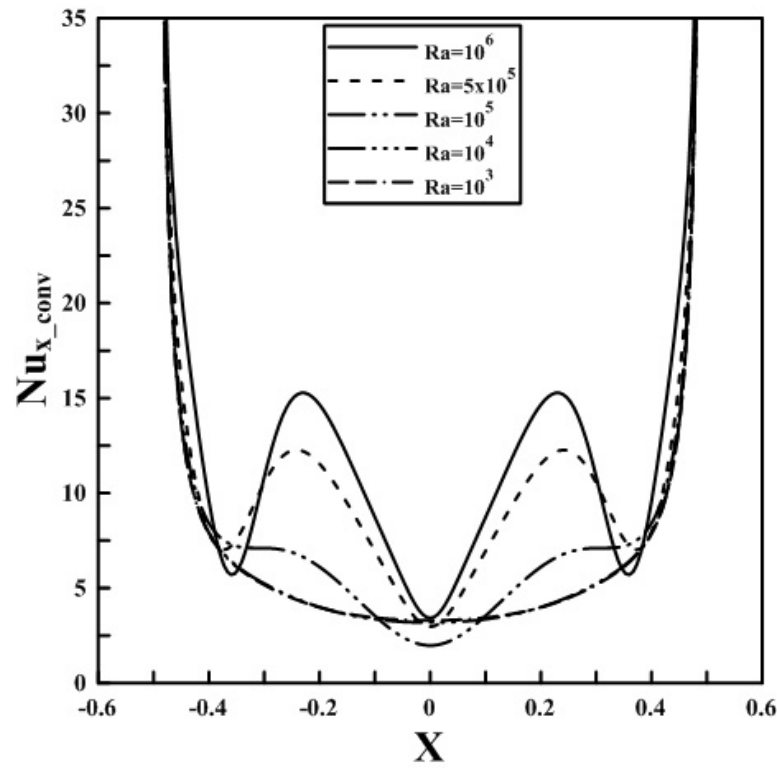

(a)

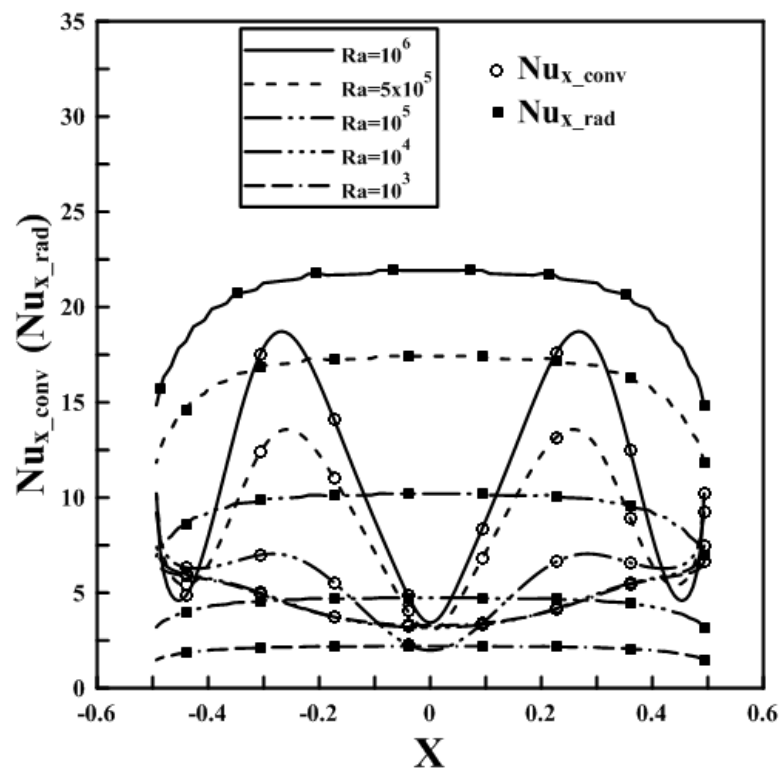

(b)

Fig. 6. Influence of the Rayleigh number on the variation of the local Nusselt number versus the distance $X(a=1 / 6, b=1 / 6$, $c=2 / 3$ ) (a) Convective Nusselt numbers Case I: (pure convection $\epsilon_{i}=0$ ). (b) Convective and Radiative Nusselt number Case II: $\left(\epsilon_{C}=0.9 ; \epsilon_{H}=1, \epsilon_{o}=0.5\right)$.

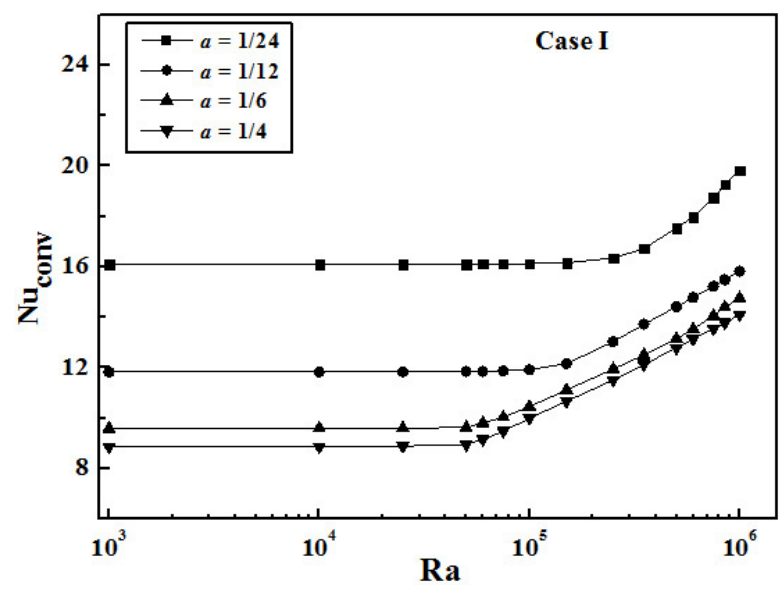

(a)

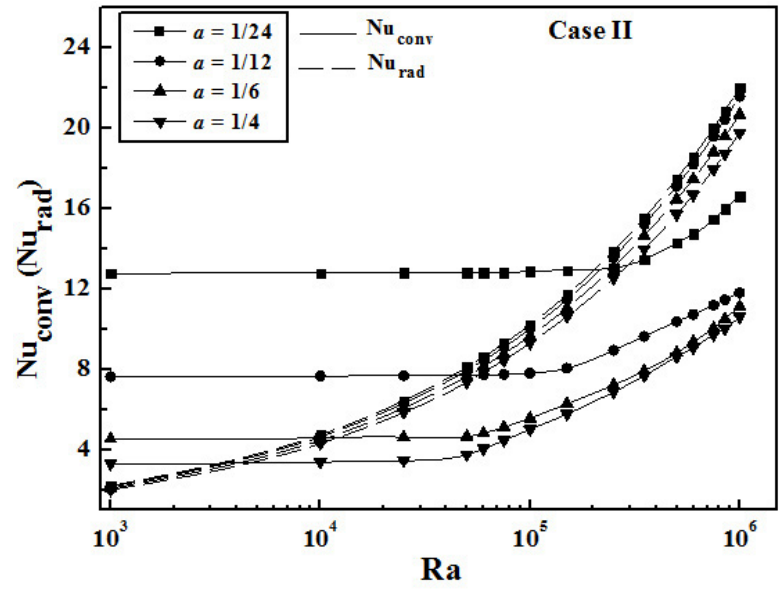

(b)

Fig. 7. Influence of aspect ratio $a$ on $N u_{\text {conv }}$ and $N u_{\text {rad }}$ at the cold wall observed for different conditions $(b=1 / 6 ; c=2 / 3)$. (a) Case I $\left(\epsilon_{i}=0\right)$. (b) Case II $\left(\epsilon_{C}=0.9 ; \epsilon_{H}=1, \epsilon_{o}=0.5\right)$.

at the transparent cover, Figures 7-9 depict the variation of mean (convective and radiative) Nusselt number with the Rayleigh number for different boundary conditions. In both cases, regardless of the aspect ratio $(a, b$ and $c$ ), when the heat transfer is only due to conduction, the Rayleigh number does not entail any significant change on convective heat transfer and $N u_{\text {conv }}$ remains unchanged whether increasing $R a$. Also, when the heat transfer is mainly due to convection, increasing the Rayleigh number produces the higher buoyancy-induced flow within the enclosure, consequently the higher convective Nusselt number. Moreover, it is observed that $N u_{\text {conv }}$ depends strongly on the enclosure height $H_{1}$ thus the aspect ratio (a) affects significantly the convective Nusselt number. This dependence is less significant by varying the depth $H_{2}(b)$ or the length $L_{2}(c)$ of the micro-cavity. It should be noted that the average convective Nusselt number increases with decreasing the cavity height $(a)$. For low $R a$ number when diffusion is dominating, the same trend is observed when $(c)$ or $(b)$ varies (i.e. increasing (b) or (c) leads to decrease Nuconv). This trend is reversed for largest $R a$ values where convection plays an important role in heat transfer. The examination of these Figures, shows that decreasing aspect ratio $(a),(b)$ or $(c)$, 


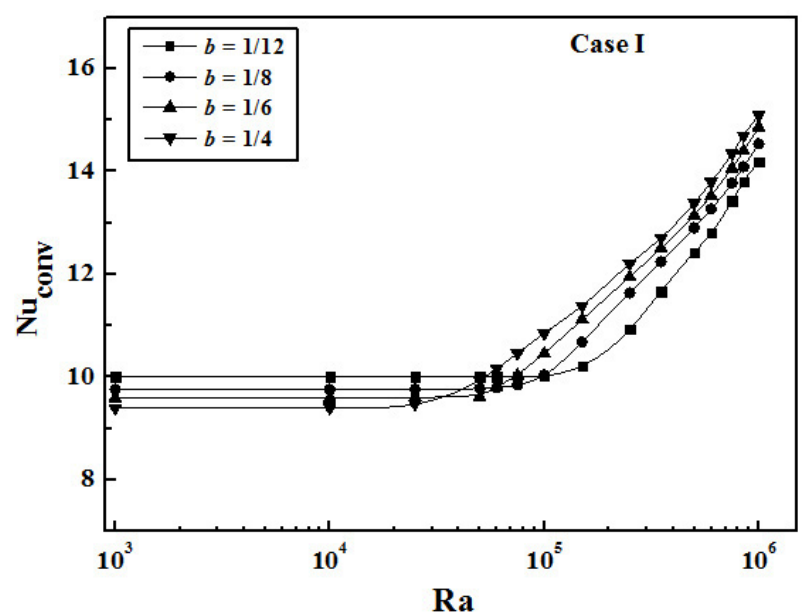

(a)

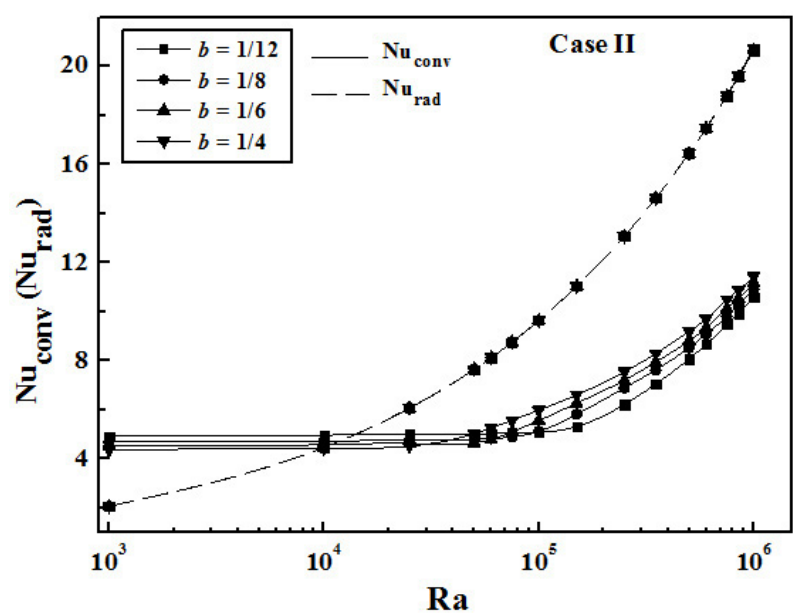

(b)

Fig. 8. Influence of aspect ratio $b$ on $N u_{\text {conv }}$ and $N u_{\text {rad }}$ at the cold wall observed for different conditions $(a=1 / 6 ; c=2 / 3)$. (a) Case I $\left(\epsilon_{i}=0\right)$. (b) Case II $\left(\epsilon_{C}=0.9 ; \epsilon_{H}=1, \epsilon_{o}=0.5\right)$.

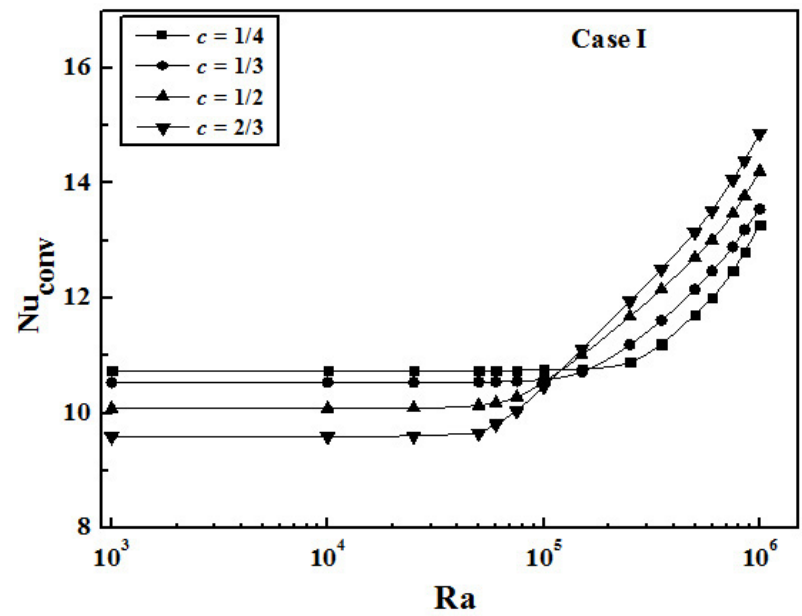

(a)

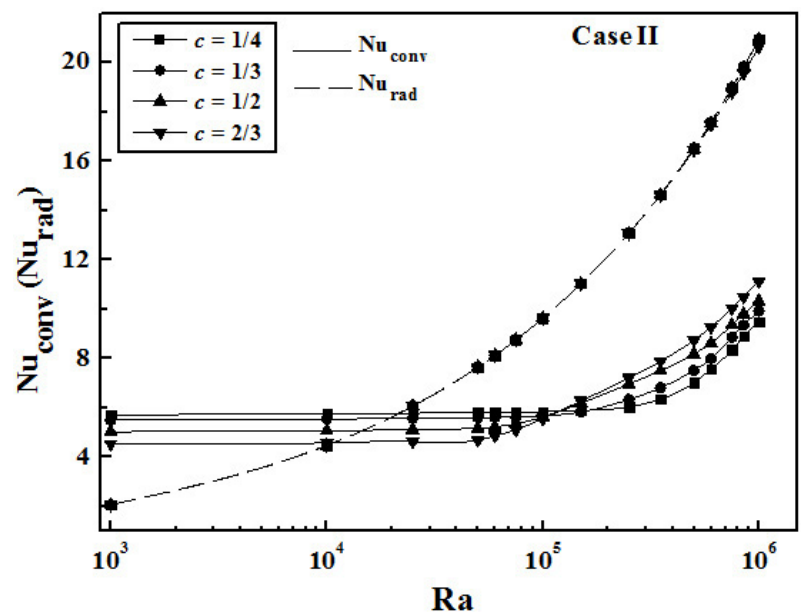

(b)

Fig. 9. Influence of aspect ratio $c$ on $N u_{\text {conv }}$ and $N u_{\text {rad }}$ at the cold wall observed for different conditions $(a=1 / 6 ; b=1 / 6)$. (a) Case I $\left(\epsilon_{i}=0\right)$. (b) Case II $\left(\epsilon_{C}=0.9 ; \epsilon_{H}=1, \epsilon_{o}=0.5\right)$.

respectively, delays the transition conduction-convection therefore extending the conduction zone. We can also conclude that the boundary condition effect in terms of convective Nusselt number is more pronounced when vertical sides are isothermal (case I) rather than adiabatic case. This is due essentially to the strengthened buoyant flow as already mentioned and confirmed by the streamlines and isotherms structures particularly in the vicinity of these sides. The contribution of the radiation exchange in the heat transfer is very important as noted in Figures $7 \mathrm{~b}-9 \mathrm{~b}$ for adiabatic boundary conditions case (II), accordingly, the overall Nusselt number is greater compared to the isothermal case (I).

The examination of these Figures, shows the variation of the average radiative Nusselt-number $N u_{\text {rad }}$ according to the Rayleigh number and different aspect ratios.
In such condition, the decreasing in the aspect ratio $(a)$ causes a significant contribution of radiative exchanges while the change in aspect ratios $(b)$ and $(c)$ has no effect on the $N u_{\text {rad }}$ regardless $R a$. Further, the radiative Nusselt number strongly depends on $R a$ number, in fact the rate of increase is more important as $R a$ is higher thus the radiation heat is a leading status vs. the convection. The largest values for $N u_{\text {conv }}$ and $N u_{\text {rad }}$ numbers correspond to the aspect ratios $(a=1 / 24, b=1 / 6$ and $c=2 / 3)$ for both cases.

\subsubsection{Influence of surface emissivity on heat transfer}

As previously shown, the radiation increases the total heat transfer markedly. Whereas the contribution of 


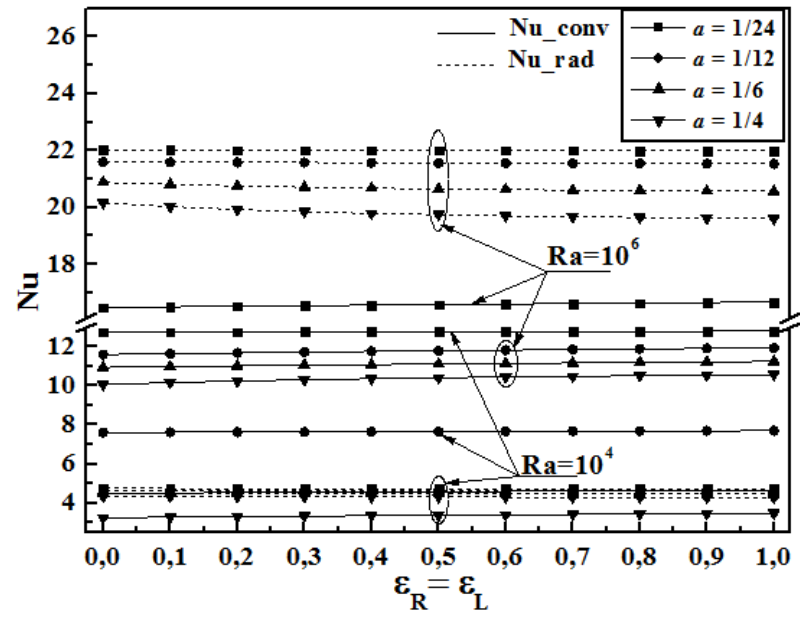

(a)

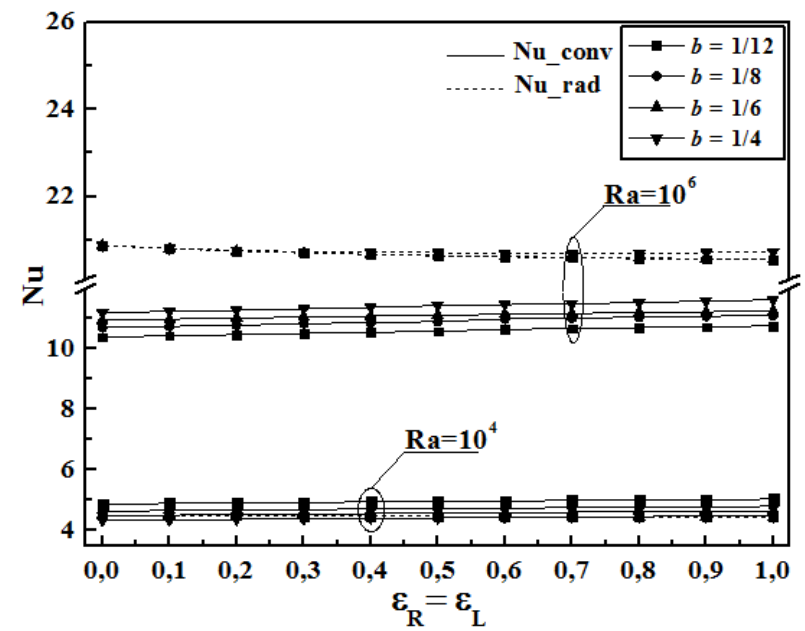

(b)

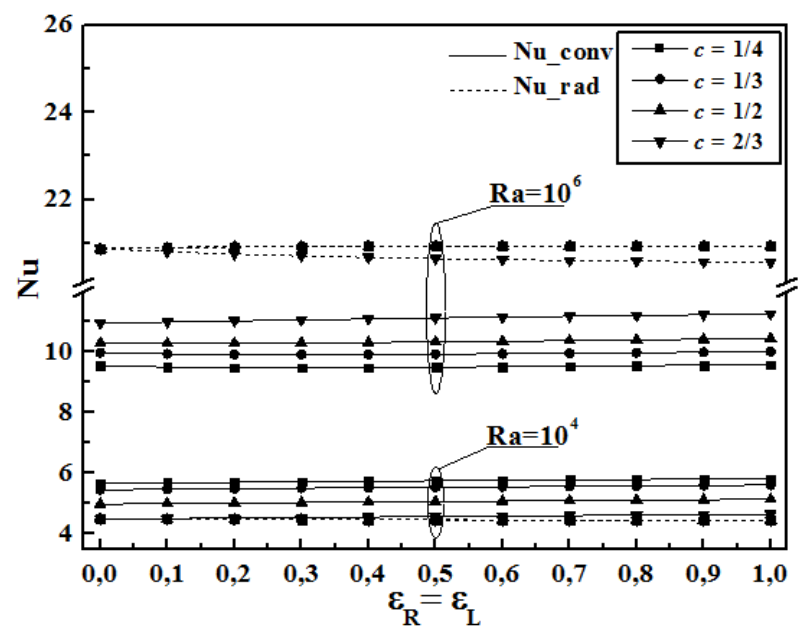

(c)

Fig. 10. Influence of the adiabatic surface emissivity $\left(\epsilon_{o}\right)$ on $N u_{\text {rad }}\left(\epsilon_{C}=0.9\right.$ and $\epsilon_{H}=1$ ). (a) $a=1 / 24$ to $1 / 4$. (b) $b=1 / 12$ to $1 / 4$. (c) $c=1 / 4$ to $2 / 3$.

radiative walls when adiabatic boundaries are considered (case II) as summarized in Table 2 highlights a slight improvement comparatively with the pure convection mode $\left(\epsilon_{i}=0\right)$. The difference does not exceed $2 \%$ for all aspect ratio. It is noteworthy that in the first case (I), if surface radiation is considered it would have no effect on $N u_{\text {conv }}$ this is due to the isothermal boundary conditions.

\section{Effect of the adiabatic walls emissivity $\epsilon_{o}$}

Figures 10a-10c show the contribution of convection compared to radiation with the emissivity of insulated sides $\epsilon_{O}$ (case II). The linear form in these figures can be due to the fact that the fluid considered is transparent and does not participate in heat transfer, only walls emissivities affect the radiative heat transfer. It is remarkable that when the shape parameter $(a)$ increases both Nusselt numbers decrease and the increase of the emissivity $\left(\epsilon_{o}\right)$ raises $N u_{\text {conv }}$ and decreases $N u_{\text {conv }}$ slightly. The same trend is observed for these Nusselt numbers when aspect ratios $(b)$ and $(c)$ decrease. Furthermore, the effect of $(b)$ and $(c)$ on $N u_{\text {rad }}$ is not important if compared with the effect of $(a)$. It will be noted that when the heat transfer is mainly due to convection $\left(R a=10^{6}\right), N u_{\text {rad }}$ is greater than the convective one. This trend is reversed in conductive regime $\left(R a=10^{4}\right)$.

\section{Effect of the cover emissivity $\epsilon_{C}$}

In the same way, for a non-zero surface emissivity, as summarized in Table 3, the radiative Nusselt number increases with increasing cover emissivity $\left(\epsilon_{C}\right)$ for all aspect ratios. It is clear for insulated boundaries (case II) when varying $(b)$ (respectively $(c)$ ) no significant effect is noticed in $N u_{\text {rad }}$ whereas it becomes larger with increasing aspect ratio $(a)$, especially for higher emissivities. 
Table 2. Comparison of $N u_{c o n v}$ between coupled mode and pure convection mode (Case II).

\begin{tabular}{ccccccccccccc}
\hline \multicolumn{10}{c}{$\left(\epsilon_{H}=1, \epsilon_{C}=0.9 ; \epsilon_{o}=0.5\right)$} \\
\hline \multicolumn{1}{c}{$a$} & \multicolumn{1}{c}{$b$} & \multicolumn{1}{c}{$c$} & \\
\hline$R a$ & $1 / 4$ & $1 / 6$ & $1 / 12$ & $1 / 24$ & $1 / 4$ & $1 / 6$ & $1 / 8$ & $1 / 12$ & $2 / 3$ & $1 / 2$ & $1 / 3$ & $1 / 4$ \\
$10^{4}$ & 3.37 & 4.58 & 7.66 & 12.78 & 4.42 & 4.58 & 4.73 & 4.97 & 4.58 & 5.07 & 5.55 & 5.76 \\
$10^{6}$ & 10.60 & 11.12 & 11.80 & 16.58 & 11.44 & 11.12 & 10.91 & 10.59 & 11.12 & 10.33 & 9.93 & 9.50 \\
\hline \multicolumn{10}{c}{} & \multicolumn{1}{c}{$\left(\epsilon_{i}=0\right)$} \\
\hline $10^{4}$ & 3.20 & 4.50 & 7.61 & 12.75 & 4.34 & 4.50 & 4.65 & 4.89 & 4.50 & 4.99 & 5.46 & 5.67 \\
$10^{6}$ & 10.07 & 10.95 & 11.61 & 16.48 & 11.27 & 10.95 & 10.74 & 10.42 & 10.95 & 10.29 & 9.98 & 9.55 \\
\hline
\end{tabular}

Table 3. Influence of transparent cover emissivity $\left(\epsilon_{C}\right)$ on $N u_{\text {rad }}$ for different aspect ratios (case II).

\begin{tabular}{ccccccccccccc}
\hline \multicolumn{10}{c}{$R a=10^{6}$} & $\epsilon_{H}=1$ \\
\hline \multicolumn{1}{c}{$a$} & \multicolumn{1}{c}{$b$} & \multicolumn{1}{c}{$c$} & \multicolumn{3}{c}{$c$} \\
\hline$\epsilon_{C}$ & $1 / 4$ & $1 / 6$ & $1 / 12$ & $1 / 24$ & $1 / 4$ & $1 / 6$ & $1 / 8$ & $1 / 12$ & $3 / 2$ & $1 / 2$ & $1 / 3$ & $1 / 4$ \\
\hline 0.1 & 2.34 & 2.42 & 2.44 & 2.47 & 2.42 & 2.42 & 2.40 & 2.40 & 2.42 & 2.42 & 2.43 & 2.43 \\
0.2 & 4.65 & 4.80 & 4.87 & 4.93 & 4.82 & 4.80 & 4.77 & 4.76 & 4.80 & 4.82 & 4.82 & 4.82 \\
0.4 & 9.13 & 9.44 & 9.70 & 9.83 & 9.54 & 9.44 & 9.42 & 9.42 & 9.44 & 9.54 & 9.55 & 9.55 \\
0.6 & 13.47 & 13.98 & 14.48 & 14.72 & 14.16 & 13.98 & 13.98 & 13.97 & 13.98 & 14.17 & 14.18 & 14.18 \\
0.8 & 17.68 & 18.45 & 19.21 & 19.58 & 18.68 & 18.45 & 18.44 & 18.44 & 18.45 & 18.70 & 18.71 & 18.71 \\
1 & 21.78 & 22.83 & 23.90 & 24.43 & 22.87 & 22.83 & 22.83 & 22.83 & 22.83 & 23.15 & 23.16 & 23.16 \\
\hline
\end{tabular}

\section{Conclusion}

Conjugate free convection and surface radiation inside partitioned enclosure filled with a transparent fluid has been carried out. The effect of several parameters such as thermal boundary conditions, surface radiation and aspect ratio for a selected range of Rayleigh number $\left(10^{3}-\right.$ $10^{6}$ ) with $\operatorname{Pr}=0.71$ have been examined. The numerical results obtained in terms of Nusselt number, streamlines and isotherms can be briefly summarized as follow:

- With the decrease of aspect ratio $(a)$, Nuconv turn stronger. The same trend is observed in diffusion regime, when varying $(c)$ or $(b)$; this trend is reversed for largest $R a$. When the heat transfer is mainly due to conduction, $R a$ does not require any significant change on $N u_{\text {conv }}$. When convection is the dominant mode, increasing $R a$ causes greatest $N u_{\text {conv }}$.

- Decreasing the aspect ratio (a) causes a significant contribution of radiative heat exchange while the change in aspect ratios $(b)$ or $(c)$ has no effect on the $N u_{\text {rad }}$ regardless $R a$.

- The increase of the emissivity $\left(\epsilon_{o}\right)$ raises $N u_{\text {conv }}$ and decreases $N u_{\text {rad }}$ slightly. For largest $R a$ values, $N u_{\text {rad }}$ is greater than $N u_{\text {conv }}$, this trend is reversed for lowest values of $R a$.

- When increasing the emissivity $\left(\epsilon_{C}\right)$, varying $(b)$ or (c) causes minor changes in $N u_{\text {rad }}$ whereas it becomes appreciable with the increase of $(a)$.

\section{References}

[1] S. Paolucci, D. Chenoweth, Natural convection in shallow enclosures with differentially heated end walls, J. Heat Transfer 110 (1988) 625-634

[2] J. Drummond, S. Korpela, Natural convection in a shallow cavity, J. Fluid Mech. 182 (1987) 543-564
[3] S. Roy, T. Basak, Finite element analysis of natural convection flows in a square cavity with non-uniformly heated wall(s), Int. J. Eng. Sci. 43 (2005) 668-680

[4] L.F. Jin, K.W. Tou, C.P. Tso, Effects of rotation on natural convection cooling from three rows of heat sources in a rectangular cavity, Int. J. Heat Mass Transfer 48 (2005) 3982-3994

[5] T. Basak, S. Roy, Amit Singh, B. Pandey, Natural convection flow simulation for various angles in a trapezoidal enclosure with linearly heated side wall(s), Int. J. Heat Mass Transfer 52 (2009) 4413-4425

[6] R.S. Kaluri, R. Anandalakshmi, T. Basak, Bejan's heatline analysis of natural convection in right-angled triangular enclosures, Effects of aspect-ratio and thermal boundary conditions, Int. J. Thermal Sci. 49 (2010) 1576-1592

[7] S.C. Saha, J.C. Patterson, C. Lei, Natural convection boundary-layer adjacent to an inclined flat plate subject to sudden and ramp heating, Int. J. Thermal Sci. 49 (2010) 1600-1612

[8] C.L. Chen, C.H. Cheng, Numerical predictions of natural convection with liquid fluids contained in an inclined arcshaped enclosure, Int. Commun. Heat Mass Transfer 39 (2012) 209-215

[9] S. Mahmud, P.K. Das, N. Hyder, A.K.M. Sadrul Islam, Free convection in an enclosure with vertical wavy walls, Int. J. Thermal Sci. 41 (2002) 440-446

[10] S. Mahmud, P.K. Das, N. Hyder, A.K.M. Sadrul Islam, Laminar free convection and entropy generation inside an inclined wavy enclosure, Int. J. Thermal Sci. 42 (2003) 1003-1012

[11] P.K. Das, S. Mahmud, Numerical investigation of natural convection inside a wavy enclosure, Int. J. Thermal Sci. 42 (2003) 397-406

[12] A. Dalal, M.K. Das, Laminar natural convection in an inclined complicated cavity with spatially variable wall temperature, Int. J. Heat Mass Transfer 48 (2005) 2986-3007 
[13] E.H. Ridouane, A. Campo, Free convection performance of circular cavities having two active curved vertical sides and two inactive curved horizontal sides, Appl. Thermal Eng. 26 (2006) 2409-2416

[14] L. Adjlout, O. Imine, A. Azzi, M. Belkadi, Laminar natural convection in an inclined cavity with a wavy wall, Int. J. Heat Mass Transfer 45 (2002) 2141-2152

[15] M. Aounallah, Y. Addad, S. Benhamadouche, O. Imine, L. Adjlout, D. Laurence, Numerical investigation of turbulent natural convection in an inclined square cavity with a hot wavy wall, Int. J. Heat Mass Transfer 50 (2007) 1683-1693

[16] S. Saha, T. Sultana, G. Saha, M.M. Rahman, Effects of discrete isoflux heat source size and angle of inclination on natural convection heat transfer flow inside a sinusoidal corrugated enclosure, Int. Commun. Heat Mass Transfer 35 (2008) 1288-1296

[17] S.H. Hussain, M.Y. Jabbar, A.S. Mohamad, Influence of presence of inclined centered baffle and corrugation frequency on natural convection heat transfer flow of air inside a square enclosure with corrugated side walls, Int. J. Thermal Sci. 50 (2011) 1799-1808

[18] M.A. Mahmoud, A.E. Ben-Nakhi, Neural networks analysis of free laminar convection heat transfer in a partitioned enclosure, Commun. Nonlin. Sci. Numer. Simul. 12 (2007) 1265-1276

[19] M. Bakkas, M. Hasnaoui, A. Amahmid, Natural convective flows in a horizontal channel provided with heating isothermal blocks: Effect of the inter blocks spacing, Energy Conversion and Management 51 (2010) 296-304

[20] W. Gao, W. Lin, T. Liu, C. Xia, Analytical and experimental studies on the thermal performance of crosscorrugated and flat-plate solar air heaters, Appl. Energy 84 (2007) 425-441

[21] Y. Varol, H.F. Oztop, Free convection in a shallow wavy enclosure, Int. Commun. Heat Mass Transfer 33 (2006) 764-771.

[22] Y. Varol, H.F. Oztop, A comparative numerical study on natural convection in inclined wavy and flat-plate solar collectors, Building and Environment 43 (2008) $1535-1544$

[23] C. Chen, C. Cheng, Predictions of buoyancy-induced flow in various across-shape concave enclosures, Int. Commun. Heat Mass Transfer 38 (2011) 442-448

[24] D. Greig, K. Siddiqui, P. Karava, An experimental investigation of the flow structure over a corrugated waveformin a transpired air collector, Int. J. Heat Fluid Flow 38 (2012) 133-144

[25] R. Nasrin, S. Parvin, M.A. Alim, Effect of Prandtl number on free convection in a solar collector filled with nanofluid, Proc. Eng. 56 (2013) 54-62

[26] F.Z. Ferahta, S. Bougoul, D. Ababsa, C. Abid, Numerical Study of the Convection in the Air Gap of a Solar Collector, Energy Proc. 6 (2011) 176-184

[27] D. Greig, K. Siddiqui, P. Karava, The influence of surface heating on the flow dynamics within a transpired air collector, Int. J. Heat Mass Transfer 56 (2013) 390-402

[28] P.-C. Huang, C.-C. Chen, H.-Y. Hwang, Thermal enhancement in a flat-plate solar water collector by flow pulsation, and metal-foam blocks, Int. J. Heat Mass Transfer 61 (2013) 696-720

[29] C. Balaji, S.P. Venkateshan, Interaction of surface radiation with free convection in a square cavity, Int. J. Heat Fluid Flow 14 (1993) 260-267
[30] C. Balaji, S. Venkateshan, Correlations for free convection and surface radiation in a square cavity, Int. J. Heat Fluid Flow 15 (1994) 249-251

[31] R.A. Kuyper, T.H.H. Van, D. Meer, C.J. Hoogendoorn, R.A.W. Henkes, Numerical study of laminar and turbulent natural convection in an inclined square cavity, Int. J. Heat Mass Transfer 36 (1993) 2899-2911

[32] M. Akiyama, Q.P. Chong, Numerical analysis of natural convection with surface radiation in a square enclosure, Numer. Heat Transfer Part A 31 (1997) 419-433

[33] N. Ramesh, S. Venkateshan, Effect of surface radiation on natural convection in a square enclosure, J. Thermophys. Heat Transfer 13 (1999) 299-301

[34] G. Desrayaud, G. Lauriat, A numerical study of natural convection in partially open enclosures with a conducting side-wall, Transfer ASME J. Heat Transfer 126 (2004) $76-83$

[35] S.N. Sing, S.P. Venkateshan, Numerical study of natural convection with surface radiation in side vented open cavities, Int. J. Therm. Sci. 43 (2004) 865-876

[36] H. Wang, S. Xin, P. Le Quéré, Étude numérique du couplage de la convection naturelle avec le rayonnement de surfaces en cavité carrée remplie d'air, C. R. Acad. Sci. Mécanique 334 (2006) 48-57

[37] A. Mezrhab, M. Jami, M. Bouzidi, P. Lallemand, Analysis of radiation-natural convection in a divided enclosure using lattice Boltzmann method, Computers and Fluids 36 (2007) 423-434

[38] R. Alvarado, J. Xamán, J. Hinojosa, G. Álvarez, Interaction between natural convection and surface thermal radiation in tilted slender cavities, Int. J. Thermal Sci. 47 (2008) 355-368

[39] M. Rabhi, H. Bouali, A. Mezrhab, Radiation natural convection heat transfer in inclined rectangular enclosures with multiple partitions, Energy Conversion and Management 49 (2008) 1228-1236

[40] G.V. Kuznetsov, M.A. Sheremet, Conjugate natural convection with radiation in an enclosure, Int. J. Heat Mass Transfer 52 (2009) 2215-2223

[41] H.F. Nouanegue, A. Muftuoglu, E. Bilgen, Heat transfer by natural convection, conduction and radiation in an inclined square enclosure bounded with a solid wall, Int. J. Thermal Sci. 48 (2009) 871-880

[42] B. Mondal, X. Li, Effect of volumetric radiation on natural convection in a square cavity using lattice Boltzmann method with non-uniform lattices, Int. J. Heat Mass Transfer 53 (2010) 4935-4948

[43] V. Vivek, Anil Kumar Sharma, C. Balaji, Interaction effects between laminar natural convection and surface radiation in tilted square and shallow enclosures, Int. J. Therm. Sci. 60 (2012) 70-84

[44] R. Li, M. Bousetta, E. Chénier, G. Lauriat, Effect of surface radiation on natural convective flows and onset of flow reversal in asymmetrically heated vertical channels, Int. J. Therm. Sci. 65 (2013) 9-27

[45] H.C. Hottel, A.F. Saroffim, Radiative Heat Transfer, Mc Graw Hill, New York, 1967

[46] S.V. Patankar, Numerical Heat Transfer and Fluid Flow, Hemisphere Publishing, New York, 1980 